\title{
Social and Political Dimensions of Identity
}

\author{
Charles D. Raab \\ University of Edinburgh
}

\section{Introduction}

This paper points up a number of issues concerning the topic of identity, to stimulate further debate and discussion without, however, solving any of the intellectual and practical problems that are inherent in this subject. It dwells on some conceptual matters and also describes some current policy and legal developments that have important implications for the way in which we understand identity and identification, as well as privacy and other matters that are closely related to these.

'Identity' is a fashionable focusing concept that indicates a host of contemporary anxieties. Whether it will have long-lasting value as a concept that crystallises and expresses these, or whether it will be overtaken by the next wave of fashion, cannot be foretold. But concerns over personal, social, national, ethnic, cultural, religious and other identities, and problems involved with verifying the authenticity of persons' claims to be who they say they are, have long been with us, and are likely to live long. So, too, may the contemporary absorption with matters of selfhood and otherhood. In addition, there are political, economic, bureaucratic and security issues around identity theft, identity fraud, identity cards, identity management, and so on, which are also likely to persist.

Philip Agre notes that identity, as a 'public, symbolic phenomenon that is located in history, culture and social structure', and one that embraces national, ethnic, selfadopted or ascribed attributes, differs from information technologists' conception of identity as 'epitomized by proper names' or by mathematical denotations in which 'the identity of a thing is strictly separate from, and prior to, its attributes' one broad conceptual distinction that characterizes discourse about identity. It is apparent that both senses are 'political', albeit in different but partially convergent ways. The former is political in that national or ethnic identities play a major part in power relations in and among jurisdictional political systems (e.g., states), and because adopted or ascribed identities affect individuals' and groups' citizenship or participation rights. The latter is political in that the identification of unique persons has always been a task carried out by states for a host of reasons to do with taxation, movement, voting, and other functions. It is the latter that is particularly relevant to the present discussion, because - as we shall see later - the development of identity cards and means of identification by states (and also the commercial sector) involves, in the first instance, the ability to distinguish among people with unique identifying characteristics. But competing concepts make this far from straightforward.

${ }^{1}$ Agre (1997): 6-7. 


\section{Issues in the conceptualization of 'Identity'}

'Identity' and 'identification' are among the most elusive and difficult concepts confronting scholars and researchers in the broad field of information studies, reflecting a welter of discourse in many other fields, including philosophy ${ }^{2}$, psychology ${ }^{3}$ and sociology ${ }^{4}$. There are many interpretations and applications of these terms that arise from different and often discrepant perspectives, modes of thought, and disciplines, and they extend to some of the further reaches of metaphysics and social and political theory. Some of this is profound and quite far-reaching into the nature of what it is to be a human being. But identity and identification are not just specialist terms used only by researchers in our various technical discourses. They feature prominently in casual everyday use by citizens, consumers, politicians, legislators, the media, public and private organisations, and many more domains as well. People are asked, 'have you got any identification?' or 'show me your ID' in public places and shops. We normally have no practical difficulty understanding what is being requested. But in other circumstances, the kinds of information included or omitted from the documents we carry around, and especially the information resources that lie behind such casual transactions, can be challenged. They might misrepresent the nature of whatever it is that is referred to when processes of identification question or verify your or my identity, or the identity of the groups or categories to which we belong or to which we are assigned. But so, too, scholarly and technical usage can overlook important implications of the management, verification, encoding and other systematisations of identity, especially when the perspectives of the people whose identities are involved are sidelined or left out of account.

The enormous and diverse literature that surrounds the term 'identity' testifies to the growing importance of identity in the politics and social life of our time. Identities are lost, sought, denied, created, challenged, changed, played with, killed for, legislated, and abolished. Some identities are personal, others are group, with the 'group' ranging in scale and space from the very intimate to the national. National identity, relating often to nationalism, is a flourishing topic in the social and political sciences, overshadowing other adjectival identities, such as gender, class, and personal with which it intersects in complex ways, sometimes helping persons to define these latter identities in regard to themselves. Identities, where they are nonphysical or non-institutional, may be categorical, denoting some 'us' or 'we', according to cultural, religious, 'ethnic', or other criteria, and the possibility of any social or biological factor or feature becoming shaped as an identifying criterion seems infinite; the question of categorization will be considered later on.

There have always been conflicts over identities. Political scientists would say that the working-out of conflicts over anything is a political process, involved with power relations. This politicizes the very subject matter itself: in this case, what it means to have or not to have a particular identity, to be given one or to be denied one or

\footnotetext{
2 E.g., Olson (2007).

3 E.g., Simon (2004); see also Raab (2005).

${ }^{4}$ E.g., Jenkins (2004); Bauman (2004).
} 
perhaps many. But political scientists would also say that power is exercised even where there is no overt conflict, and even where a potential conflict is not entered into by people because they do not expect success as an outcome, or where it is suppressed as an issue that could be resolved through political processes. Power, it is said, is exercised when people's mind-set is so shaped that they do not understand that their life, and even their conceptions of themselves and others, could be different from what it is: that is, that the normal, day-in and day-out world can not be otherwise than it is, and that cultural, social and governmental habits, practices and systems are important forces shaping this state of consciousness. And so it might be when identities are considered to be fixed in certain patterns and not subject to negotiation or change by people themselves or by others, because alternatives are inconceivable ${ }^{5}$.

The various social-scientific 'takes' on identity, although debated amongst sociologists, social and individual psychologists, or political scientists, and between different camps, make vital contributions to understanding human social and political phenomena. Let us look at some of this for a bit. Here we begin to touch on the concept of the 'self' and its relation to other facets of our identity, although this cannot be explored too far here. Susan Hekman takes the view that:

each of us possesses a coherent, core self that allows us to function as mature adults in a social world and provides us with an individual identity ${ }^{6}$.

She argues that:

Each of us possesses a personal identity that is constituted by an array of influences and experiences that form us as a unique person. These forces are both public, the hegemonic discourses that define our social life, and individual, the character and situation of those who care for us as infants, and through whom the public concepts are transmitted to us. The result of these influences is...our core self. But in addition to possessing a personal identity, each of us is subsumed under an array of public identities: woman/man; white/nonwhite; middle class/ working class, and so forth ${ }^{7}$.

Other discussions of the uniqueness, or otherwise, of the 'self', and how it relates to other forms of identity, are worth looking at as well. Sociologists and cognate scholars have debated the relationship, if any, between 'real' and 'virtual' identities, and between personal and social identities. Erving Goffman makes these distinctions in his cogent analysis of stigma and the management of 'spoiled' identity, 8 when discrepancies between who one 'is' and who one purports to be are publicly exposed, or in danger of so being. Richard Jenkins, on the other hand, finds these distinctions unhelpful, because 'all human identities are by definition social identities'9. For him, the adjective 'social' is redundant because:

${ }^{5}$ See Lukes (1974).

${ }^{6}$ Hekman (2004).

${ }^{7}$ Ibid.: 7

${ }^{8}$ Goffman (1968) [1963].

9 Jenkins (2004): 73; emphasis in original. 
'[i]dentifying ourselves or others is a matter of meaning, and meaning always involves interaction: agreement and disagreement, convention and innovation, communication and negotiation, 10 .

And also because identity is a reflexive process, rather than a fixed attribute. Therefore, he argues that, '[a]s social scientists, keen to avoid reification, we should probably only ever talk about "identification""11.

Yet some analytical distinctions are necessary. There are, indeed, both individual and collective identities and identification processes, even though these are not empirically separate but, as Jenkins insists, 'are routinely entangled with each other' ${ }^{12}$. There is also an important distinction between the internal and external aspects of identification - self-definition and definition by others - that forms the crux of Jenkins' analysis, and that indeed is pervasive in Goffman's works as well as in a great deal of other social and psychological treatments, whatever position is taken on the 'self', 'reality', and other contested concepts ${ }^{13}$. Likewise, the parallel distinction (but reflexiveness) between groups and categories is also an important cutting tool. Jenkins wants to reserve the use of the term 'virtual' to refer not to the identity that the individual presents to the world, or which the world perceives (in contrast to her 'real' identity, which is arguably a spurious concept), but to the (different) experience of an identity that persons may have despite their sharing of a name, (that is, a 'nominal' identity), or where the name changes but not the experience ${ }^{14}$. Whether there is a true and singular 'self' lying behind the multiplicity of identities and presented selves has long been debated, for instance, by Anthony Cohen ${ }^{15}$. From an anthropological angle, Cohen sees identity as relating to what he calls the 'authorial self', whose self-consciousness is ignored in many research paradigms. People play roles and enact performances in daily life, but their identity is not merely an aggregate of these. There is a political edge to this, in terms of potential conflict between persons and authorities, as we may find that an authoritatively assigned 'personhood' is at odds with the sense of self that we wish to assert as our identity. Cohen argues that it is more common than we might realise for individuals to resist the pressures of imposed classification ${ }^{16}$. Such responses are not confined only to outstanding instances of resistance to the dehumanisation of life in what Goffman calls 'total institutions ${ }^{17}$, so we should not interpret as special heroism what persons are accustomed to doing when classified by external and authoritative sources.

This is where we can cast some light on categorization and its relation to the uniqueness of identity. When individuals freely declare their adherence to available collective categories (e.g., gender, nationality, ethnicity, religion etc.), Cohen sees this

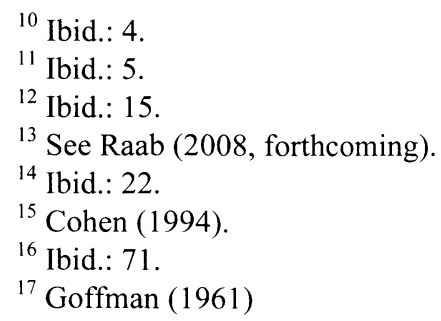


as a "means of reappropriating their identities or of creating them anew', ${ }^{18}$, rather than as giving in to pre-formed and imposed alien definitions, much less as a rejection of categorization as such as being somehow contrary to some inexpressible, solipsistic sense of a unique self. In other words, I can identify myself and tell you who I am using categories that are common and current, without feeling that I have somehow misrepresented my 'true' being. John Turner, a social psychologist, would remove the concept from the status of debatability: '[t]he self is a human universal. It is an undisputed given of human experience and life ${ }^{19}$, But that remark does not intend to support a particular interpretation of 'self' amongst a welter of alternative approaches in social psychology $\mathrm{y}^{20}$, nor is it to underplay the role of social relationships and situations in understanding the processual nature of the self and the 'adaptive flexibility of human behaviour' ${ }^{\text {, }}$. In fact, Turner criticizes the 'evils' of individualism, reification, and reductionism that remain influential in his discipline. Individualism is

the tendency to define the self as a unique, purely individual property of the person, the idea that it is about one's personal identity ...(rather than one's shared collective identities) and that it is defined by or closely related to one's personality traits or other individual-difference factors ${ }^{22}$.

Reification 'is the tendency to define the self as a thing, a mental entity stored in the cognitive system, rather than as a dynamic social psychological process ${ }^{, 23}$, and reductionism is

the tendency to seek to reduce the self-process to the functioning of simpler, more elementary processes. ... [such as] our self-interest, our motives, drives, traits, likes, dislikes, needs, fears, etc., as if these were fixed in our character independent of and prior to social interaction ${ }^{24}$.

These sources and related ones help us to ask: how do we feel about our identity? We are sometimes in two minds about our identity: wanting to conceal it and not be noticed, or to present ourselves differently to different audiences. If we belong to a minority group that is subject to discrimination in employment or social ostracism, we may sense a conflict between loyalty and a self-interested denial of membership. People with an unsavory past may wish to have it forgotten in the present by disavowing who they were. At other times, however, it may be literally in our vital interest to be distinguished from others, and not be mistaken for them. One may want to claim credit for something praiseworthy, to 'stand up and be counted', and to assert one's personal identity proudly. A fixed identity may be necessary if we are to function in daily life, and history attests to the severe difficulties that befall persons whose 'papers' have been destroyed or confiscated, and who therefore need to construct an identity. In sum, at different times and in different situations, we have

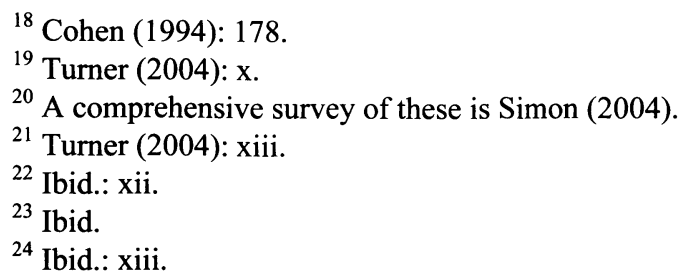


interests in both the concealment and the assertion of identity. But how do we use identity, shape it, or deny it? How do we convince others that we have a certain identity? How are identities shaped in interaction? And what scope do we have to define ourselves for ourselves?

We should not be led to thinking that it is only official, bureaucratic institutions that are engaged in information management, including the manipulation of processes for identification of unique individuals. States and companies work away at it, but so do we. Whether to offer a critique of the one is also to offer a critique of the other is a matter for debate. Everyone is in the business of information management, including the management of identity. Goffman's work shows this consistently at the level of interpersonal relations conducted in a variety of spatial and social contexts ${ }^{25}$. Goffman draws attention to 'personal identity' as the uniqueness of the individual, made up of a set of 'facts' about her that mark her off from anyone else. Personal identity is what differentiates her from others, by virtue of a 'positive mark' or 'identity peg', and her unique set of 'life history items" ${ }^{26}$. He goes on to say:

Personal identity, then, has to do with the assumption that the individual can be differentiated from all others and that around this means of differentiation a single continuous record of social facts can be attached, entangled, like candy floss, becoming then the sticky substance to which still other biographical facts can be attached ${ }^{27}$.

For Goffman, the marks and pegs in question may be, for example, images held in others' minds, or their knowledge of where the individual stands in kinship networks. They could be handwriting qualities, unique registration numbers, and the like, used in governmental organisations. Writing in the context of the quaint, but not now yet obsolete, prevailing bureaucratic technology of the 1960s, and apparently not interested to explain why the state in future would intensify its interest in identification, Goffman nonetheless had foresight of the modern, high-tech state:

[o]nce an identity peg has been made ready, material, if and when available, can be hung on it; a dossier can be developed, usually contained and filed in a manila folder. One can expect that personal identification of its citizens by the state will increase, even as devices are refined for making the record of a particular individual more easily available to authorized persons and more inclusive of social facts concerning him, for example, receipt of dividend payments $^{28}$.

This brand of sociology makes us aware that the individual's control of the information she gives out, or of the impressions that others gain about her when in her presence, is tenuous and negotiated. Moving away from the micro level of interpersonal interaction, this is perforce true of the information, whether 'hard fact' or 'soft intelligence', that flows into and out of information systems and is thereby embellished, reduced, mixed and merged, and ripened into something new that, nevertheless, be false. What can be 'managed' by me in face-to-face interactions may

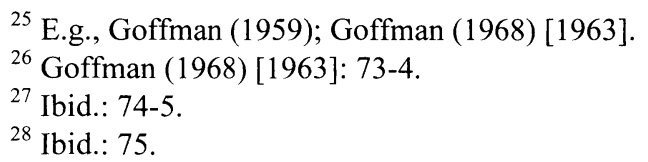


be impossible for me to 'manage' in the database, even if I were to be aware of what is located there, potentially to be managed. This, to, is of political significance. Management has to do with choice, or at least with the possibility of negotiating the terms on which choices will be made by others. But information processes and processing beyond the immediate interaction transfer most of the crucial choices from the individual to the organisation and the system. Individual voice and collective pressure have an important role to play in helping to restore these choices to the individual, but restoration can only be brought about by a system of rights and rules that, however, may simulate all or some of the conditions of personal choice, but cannot recreate them.

Contexts matter a great deal $\mathrm{n}$ all this. However, there are some identities that each of us cannot have (or claim), although the realm of impossibility is apparently smaller in online environments. Space makes a difference, too: what you can claim to be may be limited in small towns or villages where 'everyone knows everyone', but may be very wide in large cities, where 'no-one knows anyone'. Cities have been magnets for people who wanted to be unrecognized and anonymous or to change their identity. Time also makes a difference: who one is may not be who one was, although there are metaphysical complexities about this ${ }^{29}$; the networks within which one is known and in which one has an identity may change or dissolve over time, releasing one from the older identity (and from certain commitments) and making it possible to adopt a new one (and new commitments) in a newly-formed network. Because one is involved in many networks that do not dissolve simultaneously, or that do not have the possibility of completely disconnecting from one another, one cannot easily abandon one identity and take on a wholly new one without the risk of being caught out. Changes of place may reduce the risk; likewise the passage of time; likewise changes of appearance or behaviour. However, administrative records may close these escape-routes; this is an issue with regard to identity cards, and to the question whether information systems reduce the possibility of forgetting (and forgiving), which is an important element of social and individual life. But the decay-rate of identities, and the factors affecting it, need more systematic analysis.

Identities may be overt and socially or politically acknowledged, or they may be covert and cloaked in secrecy. This is historically true for certain religious groups, for example, over centuries, in circumstances where overt identification would result in persecution. Some identities are inclusive, in the sense that the threshold for adopting them is low, and dependent upon civil attributes such as residence, while others are rigidly maintained and exclusive, dependent on birth, historic or genetic factors. This is a distinction often drawn between certain national identities and others, and bears heavily on the question of citizenship, rights, and socio-cultural segregation or integration. Some identities are claimed, recognized by some or all others, but other identities cannot so easily be asserted, and may incite challenges to the claimant. Some identities are assigned, and may incite challenges by the assignee on the grounds of misclassification, and by the excluded on the same grounds. Thus, the interaction of 'objective' and 'subjective' identities is perennially created and re-

${ }^{29}$ The implications of time for identity are explored in Olson (2007). 
created, such that they reflexively shape each other, although some would deny the conceptual soundness of those two statuses. We all have multiple identities, whether simultaneously or in the course of a lifetime, and are highly unlikely to share identical 'portfolios' of these. Once again, in different contexts, we may invoke different identities, or we may validate, or at least not challenge, the identities that others consider us to have. We may also reject them. All these options require the tacit or overt agreement of others; the scope for self-determination of identity is limited, to one degree or another.

\section{3 'Identity' in Government Policy and Practice: UK Identity Cards}

Moving now from the social scientific to the governmental and organisational dimension: there appears to be a marked disjuncture between the social-scientific perspectives on identity, whatever they may be, and the worlds of government and commerce in which unique identities are the currency of practice, and in which 'identity' is not problematical, but matter-of-fact. What 'identity' means appears straightforward in the practical matter of government policy on identity cards, and in identity management schemes. Of course, there may be an untidy administrative landscape because of the diversity of identification systems that have grown up in the public administration of particular countries, and this causes problems for the efficiency, effectiveness and equitable conduct of the state. Here the problem is not seen in terms of any profound conceptual dilemmas, but as something that can be ironed out and rationalized, for example, by identity-management practices. Thus an important UK report on public services laments the welter of departmental identification processes and numbers and urges the standardization of identity management, so that

[c]itizens should reasonably expect that government should be able to easily connect to who they are at different points in service delivery. ... This can be delivered by better identity management, establishing a 'single source of truth' and be made more robust through the introduction of identity cards. ${ }^{30}$

This might be a governmental 'take' on Goffman's idea of 'identity pegs'.

A more detailed example of this emphasis on the facticity of identity can be found in the UK's Identity Cards Act 2006, which illustrates the construction of an identity through many pieces of information about a person, stored in a National Identity Register, each of which ostensibly contributes to the formation of a profile. Section 1(5) of the Act provides for the establishment of a record of 'registrable facts' about every person in the country. These are:

(a) his identity;

(b) the address of his principal place of residence in the United Kingdom;

(c) the address of every other place in the United Kingdom or elsewhere where he has a place of residence;

${ }^{30}$ HM Treasury (2006): 39-40 
(d) where in the United Kingdom and elsewhere he has previously been resident;

(e) the times at which he was resident at different places in the United Kingdom or elsewhere;

(f) his current residential status;

(g) residential statuses previously held by him;

(h) information about numbers allocated to him for identification purposes and about the documents to which they relate;

(i) information about occasions on which information recorded about him in the Register has been provided to any person; and

(j) information recorded in the Register at his request.

Note that the individual's 'identity' is a registrable fact, defined in Section 1(6) as

(a) his full name;

(b) other names by which he is or has previously been known;

(c) his gender;

(d) his date and place of birth and, if he has died, the date of his death; and

(e) external31 characteristics of his that are capable of being used for identifying him.

Other 'facts' about the person nay be imagined, but they are not considered 'registrable': for example, marital and employment statuses (and details), education, religious affiliation, medical history, and attributes by which the person is both well known and in good company with thousands or millions of others: a longstanding love of ice cream, of Ingmar Bergman films, or of Spanish holidays. These are evidently considered irrelevant to the purposes envisaged for the identity card scheme, yet I - and significant others - may consider that these facts are inherent parts of my identity, and sometimes more important to the way I identify myself, presents myself to the world, and is perceived by that world, than my other names or my facial geometry.

Schedule 1 of the Act further specifies a very long list of other recordable information. It construes these registrable five, plus previous and current residential addresses, as 'personal information', which is separate from 'identifying information' (but, confusingly, not from 'identity', as indicated in Section 1) about an individual, which is now described as

(a) a photograph of his head and shoulders (showing the features of the face);

(b) his signature;

(c) his fingerprints;

(d) other biometric information about him.

By implication, identification, curiously, here has to do with the body, and not with what is otherwise considered 'personal'. Other recordable information mentioned in Schedule 1 has to do with: one's UK residential status; thirteen personal reference numbers on various kinds of document; one's previously recorded details and any changes to those; nine different forms of particulars concerning one's identity card registration as well as its history; a further set of validation information relating to the

31 The Bill that preceded the Act said 'physical'. The Act's Explanatory Notes, no. 19, explains that 'external' means, for example, biometric information. 
latter; several kinds of security information; and information about the disclosure of register information to third parties. These total more than fifty pieces of information. Moreover, Section 3(6) gives the Secretary of State the power to modify the Schedule 1 inventory, with parliamentary approval. This may require further primary legislation, because the new information must be consistent with the Act's statutory purposes.

Thus the 'facts' about identity are seen to be those that are so construed through political decision-making processes and thus inscribed in the National Information Register as an administrative surveillance information system by which persons are identified and classified, and with which crucial decisions are to be taken about persons' rights and claims. It is normally very difficult or impossible for us to control the identities that are ascribed to us by the 'factual' categories in which information is collected, stored, and further processed. But note, once again, that the establishment of uniqueness and differentiation through these procedures involves decisions about what categories are to be used in the universal framework, thus pointing up the importance of categorization in identity processes. The 'facts' of identity are intended to establish the uniqueness of the individual, but we may observe that uniqueness is only one dimension of what we consider our identity. I may identify myself as a member of a very large number of groups, categories, collectivities, and so on, and these help to form my 'identity', however unique I may be.

\section{4 'Identity' in Public Services}

The public services, and so-called 'e-government', are important sites for observing the way identities and identification processes enter into daily life, and are managed. In many countries, public services are increasingly being provided within a 'citizenfocused' or 'citizen-centric' policy framework. It aims to abandon an impersonal mode of service provision that is held to have characterized a patronizing post-war welfare state, and to move towards a mode that tailors services to citizens and takes their views and needs into account. There is a mixture of individuation and classification or categorization in these e-government initiatives that prompts further discussion about the way persons are identified for services. In passing, we may note that 'services' are of different kinds. They include those that provide benefits, while others involve the application of sanctions and controls. Each of these types can apply universally to all, or they can be targeted on certain groups, categories, or persons. Some services are preventative, while others are remedial. This gives several somewhat different contexts in which identification may be required, and which are therefore different 'ecologies' for information and organisational systems and their effects. 
These distinctions will not be developed here in any detail; they feature in other work $^{32}$. But they indicate that we should perhaps explore the differences between what is needed for identification in different administrative settings, and how the identity management systems can be tailored to these different requirements, where the risks and consequences of misidentification vary. This is because the sharing of data on citizens in each of these settings features different patterns of opportunity for consent, objection, mandatory requirement, and so on, shaped by the legislation and the administrative or professional practices involved in each of these types: for instance, as regards information systems involved in the control of offenders, as contrasted with those involved in providing care for caring for unemployed single parents. Or shaped by whether the requirement is the predictive identification of those likely to commit certain offences, as contrasted with the predictive identification of those likely to become unemployed with dependent children.

The drive towards citizen-focused government is built upon ancient characteristics of bureaucracies, and include novel developments of technical systems for locating, identifying and recording individuals and for authenticating their claims. New information technologies are seen as the key to the prospect of personalising the claims and rights of citizenship or membership in a political community. The point is put in the following extract relating to this policy from a United Kingdom (UK) website $^{33}$ :

Government is delivering services in a way and at a time that suits the needs of each person. ... Individualising public services delivery is not a new idea, but one that is slowly becoming a reality, thanks to technology. Monolithic, 'one size fits all' government is fast becoming obsolete. ...

With technology everyone, in the eyes of the government at least, is equal. With technology your geographic location, your economic and social status, whether you are disabled, homeless, working nights, rich or poor, all that in theory, becomes irrelevant. ...

Personalising citizen services goes beyond convenience. We can use them to confront the problems of inequality, an aging population, greater competition and global security with ideas, innovation and opportunity.

This is not an appropriate place to debate or rebut the premises or conclusions of citizen-centric government in its electronic version. There are certainly creditable social-policy ideals in this departure. Personalising services may be a considerable improvement in governmental provision, and may be a way of addressing deep-rooted problems of inequality and disadvantage. But it is important to note what is left out of consideration in such a statement, or what is rebuttable in the egalitarian premise about technology.

By Perri 6, Christine Bellamy and the author in writing related to a completed ESRCfunded research project on 'Joined-up Public Services: Data-sharing and Privacy in Multiagency Working', Grant No. RES/000/23/0158.

33 http://www.govx.org.uk/communities/spaces/citizenservice/; accessed 15/4/07; the quoted item was created 25/8/06, and is hosted by GovXChange - A SOCITM Information Age Group (SIAM) Initiative. SOCITM is the Society of Information Technology Management, which relates to local government and the public sector in the UK. 


\section{Privacy and 'Personal Data': The Case of RFID}

Here, another concept enters the picture: privacy. The very means of personalization, and therefore the crucial means and infrastructures for implementing citizen-centric policy, poses a potential danger to privacy that has consequences wider than the infringement of privacy itself, alongside the benefits that personalization, and indeed, certain kinds of surveillance, may bring to individuals and to state systems.

The statement quoted immediately above gives no indication that governments, which are often politically, legally and morally committed to protect citizens' privacy, including information privacy, have been grappling with the question of protection in their plans for personalized, proactive service provision for many years, 34 and that answers have been difficult to give and to enshrine in policy that would reconcile the tension between conflicting objectives. Yet it must also be said that the momentum of public-service policy, including perhaps especially the law-enforcement and sanctioning side, makes it tempting for governments to underplay or to ignore their privacy commitments and to seek to maximize, rather than to limit, the utilization of personal information and the surveillance techniques through which much of these data are gathered.

But 'privacy' itself is a further ambiguous concept, as is evident through several decades or more of scholarly debate, policy-making and legal rulings. There are many 'takes' on 'privacy', which are too well known to require elaboration here; they will be touched on again later. Conflicts over identity and identification are, in part, conflicts over the extent to which privacy should be respected. But what is protected or invaded when privacy is protected or invaded cannot be taken for granted, whether in one legal jurisdiction or across many jurisdictions. This has a bearing on critical approaches to surveillance and to several kinds of practical measures: for example, to make technologies 'privacy friendly', to provide privacy statements for online consumers, to avoid the use of personal details of individuals where possible by providing the means for anonymisation when it is only necessary to verify entitlement, and to assess the impact of new developments on privacy.

This brings us a little closer to the question of the characteristics that are thought to constitute our personal data. What, in fact, counts as 'personal data', and how the definition of this can be inscribed in legislation and therefore reflected in information processing, has been a matter of come uncertainty for a few years, at least in the United Kingdom but also within the European Union more generally. 35

Radio frequency identification (RFID) is one development in which we can see how the definition of 'personal data' matters. A good source for this is the debate in and around the European Union's Article 29 Working Party, which was established under the Data Protection Directive 95/46/EC; illustrative quotations from its 2005 'Working document on data protection issues related to RFID technology' will be given at some length.36 It argued that, depending upon the particular application in

\footnotetext{
${ }^{34}$ See for example, Cabinet Office (Performance and Innovation Unit) (2002).

${ }^{35}$ This is discussed further in Raab (2005).

${ }^{36}$ Article 29 Data Protection Working Party (2005a).
} 
which RFID technology is used, personal data may or may not be involved; and if it is not, then the Directive does not apply. The Working Party said:

In assessing whether the collection of personal data through a specific application of RFID is covered by the data protection Directive, we must determine (a) the extent to which the data processed relates to an individual and, (b) whether such data concerns an individual who is identifiable or identified. Data relates to an individual if it refers to the identity, characteristics or behaviour of an individual or if such information is used to determine or influence the way in which that person is treated or evaluated. In assessing whether information concerns an identifiable person, one must apply Recital 26 of the data protection Directive which establishes that 'account should be taken of all the means likely reasonably to be used either by the controller or by any other person to identify the said person'. (paragraph 4.1; original emphases removed)

Recital 26 will be mentioned again at a later point. But we can see that the question turns on the definition of 'personal data', and those who are eager to implement RFID technology, and those who are hostile to it, have each pressed for the kind of interpretation that would support their position. Following a period of consultation, the Working Party issued another paper that briefly reported on the consultation results, and that pointed out the clash in opinion over the definition of 'personal data' as between - broadly speaking - the IT industry and retailers, on the one hand, and universities, consumers and think tanks, on the other.37

More recently, the debate has been taken further within the European Union by means of a new paper produced by the Article 29 Working Party.38 The Working Party's 'Opinion 4/2007 on the concept of personal data', adopted on 20 June 2007, aimed to resolve uncertainty among the diverse practices of EU Member States in which 'personal data' had different meanings, and to elaborate and justify a definition. They said that the definition of the concept had a deep impact on matters to do with identity management and RFID, and their paper argued for a wider definition in keeping with the Directive; by implication, not one that would favour industry. The Working Party put forward three alternative criteria for judging whether data 'relate' to an individual, as follows:

....in order to consider that the data 'relate' to an individual, a 'content element OR a 'purpose' element OR a 'result' element should be present. The 'content' element is present in those cases where...information is given about a particular person, regardless of any purpose on the side of the data controller or of a third party, or the impact of that information on the data subject. ...For example, the results of medical analysis clearly relate to the patient, or the information contained in a company's folder under the name of a certain client clearly relates to him. Or the information contained in a RFID tag or a bar code incorporated in an identity document of a certain individual relates to that person, as in future passports with a RFID chip. ... That 'purpose' element can

${ }^{37}$ Article 29 Data Protection Working Party (2005b).

${ }^{38}$ Article 29 Data Protection Working Party (2007). 
be considered to exist when the data are used or are likely to be used...with the purpose to evaluate, treat in a certain way or influence the status or behaviour of an individual. (p. 10; original emphasis removed)

... when a 'result' element is present. ... data can be considered to 'relate' to an individual because their use is likely to have an impact on a certain person's rights and interests. ... it is not necessary that the potential result be a major impact. It is sufficient if the individual may be treated differently from other persons as a result of the processing of such data. (p.11; original emphasis removed)

The Working Party then went on to clarify what it means for someone to be identified or identifiable, with regard to what the Directive said about this. They wrote:

...a natural person can be considered as 'identified' when, within a group of persons, he or she is 'distinguished' from all other members of the group. Accordingly, the natural person is 'identifiable' when, although the person has not been identified yet, it is possible to do it....Identification is normally achieved through particular pieces of information which we may call 'identifiers' and which hold a particularly privileged and close relationship with the particular individual. Examples are outward signs of the appearance..., like height, hair colour, clothing, etc... or a quality...which cannot be immediately perceived, like a profession, a function, a name etc. (p.12; original emphasis removed)

They then went on to distinguish direct and indirect ways of identification. Direct identification typically involves a name, but perhaps with other corroborating direct information to distinguish a specific individual. Indirect identification relies on 'unique combinations' that may involve categories, such as age or regional origin. But the distinction between identifying someone and their identifiability is particularly interesting, because it illustrates the social, economic, policy and other processes that provide the context for this, and not merely the technical infrastructures. Let us recall that the Directive, in Recital 26, said that identifiability relates to 'all the means likely reasonably to be used either by the controller or by any other person to identify the said person'. Thus the Working Party said of this criterion:

This means that a mere hypothetical possibility to single out the individual is not enough to consider the person as 'identifiable'. If...that possibility does not exist or is negligible, the person should not be considered as 'identifiable', and the information would not be considered as 'personal data'. The criterion...should in particular take into account all the factors at stake. The cost of conducting identification is one factor.... The intended purpose, the way the processing is structured, the advantage expected by the controller, the interests at stake for the individuals, as well as the risk of organisational dysfunctions (e.g. breaches of confidentiality duties) and technical failures should all be taken into account. ...[T]his test is a dynamic one and should consider the state of the art in technology at the time of the processing and the possibilities for development during the period for which the data will be processed. Identification may not be possible today with all the means likely 
reasonably to be used today. ...However, $\mathrm{i}[\mathrm{f}]$ they are intended to be kept for 10 years, the controller should consider the possibility of identification that may occur also in the ninth year of their lifetime, and which may make them personal data at that moment. The system should be able to adapt to these developments as they happen, and to incorporate then the appropriate technical and organisational measures in due course. (p. 15; original emphases removed)

The reason that this rich example has been dwelt upon in this paper is that it points up the effect that the decisions taken by those who use information about identities or who design and implement information systems in social, business and government organisations has upon the construction of a definition, such that it comes within or remains outside the scope of the law. This is important in any attempt to understand the politics of personal identity; we need to know more about the way these decisions are taken, what the patterns of interests and pressures may be that influence the decisions, what the discourses are amongst decision-makers, and whether there are likely to be sufficient safeguards surrounding the identification of individuals, in view of the potential harms that may result. On the other hand, many would say that the question of harm from identification should not be pre-judged; or, in a related way, that surveillance, which is very closely connected with the identification and identifiability of persons, should not be seen only in negative terms.

\section{Conclusion: The 'Public Interest' and Privacy}

Finally, a further controversial and ambiguous concept comes into play in these circumstances in which information systems are involved in identifications: the 'public interest', which can be juxtaposed to 'privacy'. The concept of 'public interest' is increasingly invoked as part of the legitimizing justification for information systems, technologies and processes that form the infrastructure for citizen-centric government. The public interest is said to be served by more efficient and effective provision of public services, including the sanctions side of public services - for example, anti-fraud operations - through the intensive and extensive use of databases of personal information and by improved methods of identity management. It is also invoked in certain situations where public protection is thought to override the concealment of identity, as in cases where the geographical location of pedophiles is concerned. We also find a variation of it, in the form of 'public safety' or 'security', especially in contexts where national borders, immigration, terrorism and the like are the subject of policy-making. Identity cards are at the forefront of these safety and security contexts. The old (and discredited) slogan, 'if you have nothing to hide, you have nothing to fear', is often deployed and applied not only to information about persons, but about their very identity; anonymity is said to be the shield for untrustworthy or criminal elements in society, against whom the public interest lies in revealing who they are and what they are.

The problem with counterposing a value like the 'public interest' against privacy and anonymity is that, in the current political climate across many countries, it too easily becomes the trump card over those competing values. In situations of conflict, 
this arises when policy-makers argue that there should be a 'balance' struck between different values or purposes involving information collection and processing, including information about identities. Whether there really is a conflict, and whether it is best stated as a conflict between privacy and the public interest, depends on how we understand the concept of 'privacy'. Exploring this would take us too far afield here, but it is certainly high on an agenda for theoretical development in this field, for it has not yet been sufficiently addressed in theory or in policy discourse. It turns on whether privacy is only a matter concerning individual rights and claims, or whether the beneficiaries of privacy protection are societies as a whole, and indeed the 'public interest', and not just the individual citizen or customer. The social values of privacy, and its value to the maintenance of democratic political communities, have been recognized by many writers 39 , but have been largely ignored in policy discourse, and in much of the discourse on rights as well. It may well be that we are dealing with two competing conceptions of the public interest, and not a contest between the claims of the individual and the claims of society. That puts it at the forefront of political theory and the study of public policy. This issue, and the other ones reviewed in this paper, resonate with long-standing debates about human life, citizenship, and the state; these are, indeed, very big subjects.

\section{References}

1. Agre, P. (1997) 'The Architecture of Identity: Embedding Privacy in Market Institutions', Information, Communication and Society, 2,1: 1-25.

2. Article 29 Working Party (2005a) Working Document on Data Protection Issues Related to RFID Technology, WP 105, January 19, 2005, 10107/05/EN, available at: http://ec.europa.eu/justice_home/fsj/privacy/docs/wpdocs/2005/wp105_en.pdf, accessed 27 November 2007.

3. Article 29 Working Party (2005b) Results of the Public Consultation on Article 29 Working Document 105 on Data Protection Issues Related to RFID Technology, WP 111, 28 September 2005, 1670/05/EN, available at: http://ec.europa.eu/justice_home/ fsj/privacy/docs/wpdocs/2005/wp111_en.pdf, accessed 27 November 2007.

4. Article 29 Working Party (2007) Opinion $4 / 2007$ on the Concept of Personal Data, WP 136, 20th June 2007, 01248/07/EN, available at: http://ec.europa.eu/justice_home/fsj privacy/docs/wpdocs/2007/wp136_en.pdf, accessed 27 November 2007.

5. Bauman, Z. (2004) Identity: Conversations with Benedetto Vecchi, Cambridge: Polity Press.

6. Bennett, C. and Raab, C. (2006) The Governance of Privacy: Policy Instruments in Global Perspective, 2nd edn., Cambridge, MA: MIT Press.

7. Cabinet Office (Performance and Innovation Unit) (2002) Privacy and Data-Sharing: The Way Forward for Public Services, available at: http://www.cabinetoffice.gov.uk/ upload/assets/www.cabinetoffice.gov.uk/strategy/piu-data.pdf, accessed 27 November 2007.

8. Cohen, A. (1994) Self Consciousness: An Alternative Anthropology of Identity, London: Routledge.

${ }^{39}$ E.g., Westin (1967); Schoeman (1992); Regan (1995); Bennett and Raab (2006). 
9. Goffman, E. (1959) The Presentation of Self in Everyday Life, New York, NY: Doubleday Anchor.

10. Goffman, E. (1961) Asylums: Essays on the Social Situation of Mental Patients and Other Inmates, New York, NY: Doubleday Anchor.

11. Goffman, E. (1968) [1963] Stigma: Notes on the Management of Spoiled Identity, Englewood Cliffs, NJ: Prentice-Hall.

12. Hekman, S. (2004) Private Selves, Public Identities: Reconsidering Identity Politics, University Park, PA: Penn State University Press.

13. HM Treasury (2006) Service Transformation: a Better Service For Citizens and Businesses, a Better Deal for Taxpayers (Review by Sir David Varney), available at: http://www.hm-treasury.gov.uk/media/4/F/pbr06_varney_review.pdf, accessed 27 November 2007.

14. Jenkins, R. (2004) Social Identity, 2nd edn., London: Routledge.

15. Lukes, S. (1974) Power: A Radical View, London: Macmillan.

16. Olson, E. (2007) 'Personal Identity', in Zalta, S. (ed.), The Stanford Encyclopedia of Philosophy (Spring 2007 Edition), available at: http://plato.stanford.edu/archives/ spr2007/entries/identity-personal; accessed 27 November 2007.

17. Raab, C. (2005) 'Perspectives on "Personal Identity", BT Technology Journal, 23, 4: 1524.

18. Raab, C. (2008, forthcoming) 'Identity: Difference and Categorization', in Kerr, I., Lucock, C. and Steeves, V. (eds.), On the Identity Trail: Privacy, Anonymity and Identity in a Networked Society.

19. Regan, P. (1995) Legislating Privacy: Technology, Social Values and Public Policy, Chapel Hill, NC: University of North Carolina Press.

20. Schoeman, F. (1992) Privacy and Social Freedom, Cambridge: Cambridge University Press.

21. Simon, B. (2004) Identity in Modern Society: A Social Psychological Perspective, Oxford: Blackwell.

22. Turner, J. (2004) 'Foreword', in Simon, B. (2004) Identity in Modern Society: A Social Psychological Perspective, Oxford: Blackwell.

23. Westin, A. (1967) Privacy and Freedom, New York, NY: Atheneum. 